\title{
Fostering experimental competences of prospective physics teachers
}

\author{
Philipp Bitzenbauer*๑ and Jan-Peter Meyn $\odot$ \\ Department Physik, Professur für Didaktik der Physik, Friedrich-Alexander-Universität \\ Erlangen-Nürnberg, Staudtstraße 7, Erlangen D-91058, Germany \\ E-mail: philipp.bitzenbauer@fau.de
}

\begin{abstract}
Physics teachers are often faced with the challenge of having to set up difficult experiments, or they have to consciously manipulate parameters in order to be able to demonstrate a phenomenon convincingly. Comprehensive laboratory courses are standard procedure in any study program for prospective physics teachers. However, many students, even after completing standard laboratory courses, show difficulties in standard experimental situations, such as measuring an electric current. We report on a new seminar concept for students in physics teacher study programs. This concept is based on the current state of research in physics education, on the teachers' professional competences, and on the modelling of experimental competence, justifying its embedding in teacher training. We present first results of a pilot study carried out to evaluate the seminar.
\end{abstract}

Keywords: experimental competence, teacher education, professional knowledge, assessment

\section{Experimental competences in teacher studies}

Experiments are a central component in physics lessons at the secondary school level $[1,2]$ and are

* Author to whom any correspondence should be addressed.

Original Content from this work may be used under the terms of the Creative Commons Attribution 4.0 licence. Any further distribution of this work must maintain attribution to the author(s) and the title of the work, journal citation and DOI. by some even seen as the defining characteristic of physics curricula [1, p 655]. Thus, fostering experimental competences of prospective physics teachers is an important learning target in teacher education and various approaches are being pursued and investigated to achieve this goal [3].

When we discuss ways to enhance experimental competences of prospective physics teachers in the course of teacher training, we must embed the construct experimental competence into the model of teachers' professional competences [4-7]. We argue that meaningful 


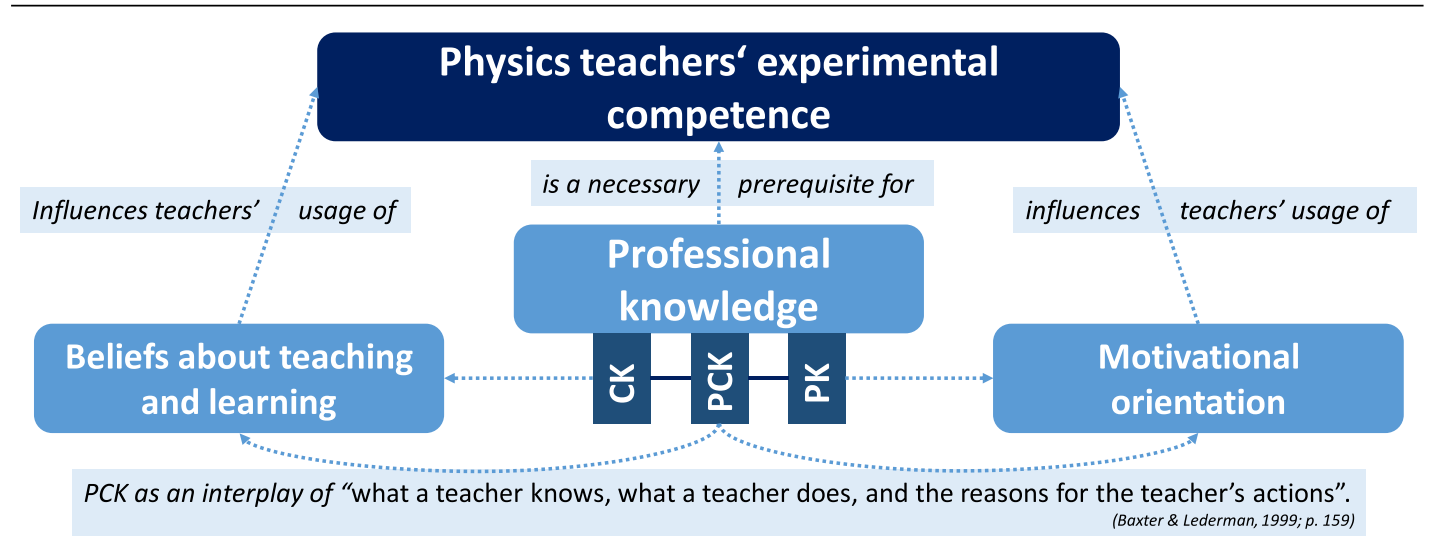

Figure 1. Experimental competence as we locate it within the model of teachers' professional competence, following Baumert and Kunter [4]. Thus, in this article we suggest that experimental competence of prospective physics teachers must not only be encouraged in the context of laboratory courses (focusing on CK), but also in the context of didactic education (linking CK and PCK), cf [8], because PCK can be regarded an interplay of 'what a teacher knows, what a teacher does, and the reasons for the teacher's actions' [9, p 159].

experimentation in the classroom requires high standards in all respects: namely in content knowledge (CK), pedagogical content knowledge (PCK) and pedagogical knowledge, as well as in beliefs about teaching and learning, and motivational orientations. Therefore, all parts of the model should be regarded the sine qua non for the teachers' experimental competence (see figure 1).

During their studies, prospective physics teachers are expected to improve their fundamental experimental competences by completing laboratory courses mainly focusing on the prospective teachers' CK. The learning goals that can usefully be pursued with such laboratory courses are indicated by The American Association of Physics Teacher's proposals [10], and reference [11] shows how these can be operationalised in practice. Usually, learning goals for laboratory courses cover everything from students' understanding of physical content and learning about experimental measurements or uncertainties to the development of communication skills [12]. At many universities, traditional introductory lab courses are related to introductory lecture courses with an emphasise on fostering experimentation skills or with the aim to reinforce course content because 'the underlying rationale is that students will better understand the physics if they conduct experiments and see for themselves how the physics principles work in real life' [12, p 38].

\section{Physics education research on laboratory courses}

While empirical research on physics lecture courses has long been established in the physics education research community [13], systematic research on the effectiveness of laboratory courses has only recently been advanced, e.g. [14-21]: These studies' results reveal a rather sobering picture for laboratory courses, as their learning effectiveness has been doubted by various researchers [22, 23]. For example, Wieman and Holmes question the effectiveness of laboratory courses in supporting mastery of physics content [14]. Specifically, Holmes et al found no measurable effect on students' course performances when researching lab courses [18].

With respect to the students' cognitive activities in lab courses, the empirical findings are also not very promising. In the summary of their study on the cognitive activities engaged in undergraduate laboratory courses, Holmes and Wieman state:

'While it is understandable that lecture courses would not engage students in cognitive tasks involved in physics experimentation, the lack of exposure in traditional lab courses where students are conducting experiments may seem surprising' [17, p 9]. 
Fostering experimental competences of prospective physics teachers

Holmes and Wieman explain their finding in another article by stating that the students' only thinking in the laboratory courses 'was in analysing data and checking whether it was feasible to finish the lab in time' [12, p 40]. As the central cause for this finding, the authors identify the structure of typical laboratory courses because

'if you break down the elements of a typical lab activity, you realize that all the decision making involved in doing experimental physics is done for the students in advance. The relevant equations and principles are laid out in the preamble; students are told what value they should get for a particular measurement or given the equation to predict that value; they are told what data to collect and how to collect them; and often they are even told which buttons to press on the equipment to produce the desired output' [12, p 40].

This finding is in accordance with those of previous studies in different settings, e.g. on lab work in schools: the constant concern of students in typical laboratory courses is to cope with tasks within the given constraints, which can hinder an effective learning process [24, 25].

Thus, although several studies do also indicate potential values of such lab courses, e.g. fostering the students' attitudes and beliefs about experimental physics [20] or the students' experimentation-focused critical thinking skills [21], the effectiveness of fostering experimental competences through typical laboratory courses must be questioned: 'by working on a common template, students, strictly following the instructions, can safely perform the work, being not fully aware of the essence of the experiment conducted' [26]. The instructions given are worked through by students during the laboratory courses, but this seems to promote the acquisition of experimental competences only to a limited extent, as hardly any complex decision-making situations have to be mastered [27]. So 'the typical laboratory experience $[\ldots]$ is a hands-on but not a minds-on activity' [28].

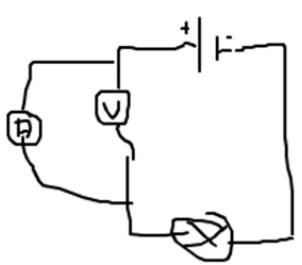

Figure 2. Sample sketch of test person P24A in our pre-test, preparing the measurement of electric current and voltage in an electric circuit. Student P24A suggested measuring voltage in series, with the electrical current parallel to the voltmeter. In doing so, he is no statistical outlier. We provide deeper insight into the design and the evaluation of our new seminar concept in this article.

In fact, it is not only the complex experiments that cause difficulties for students, even when they were formally successful participants in these lab courses. Even standard experimental situations, that occur in everyday classroom situations, such as measuring an electric current or determining the focal length of a lens, may bewilder students. We confirmed these findings with the results of a pre-test within a pilot study with prospective physics teachers $(\geqslant 5$ th semester), evaluating a new seminar concept which we present in section 4. Figure 2 shows the sketch on how to measure current and voltage from our pre-test by a student teacher in 5th semester, after the completion of two laboratory courses.

Our new seminar concept is intended to solve the problem. We provide an additional way to complement traditional laboratory courses, with a view to advancing the experimental competences of prospective physics teachers. It is particularly important to us that the prospective physics teachers have the opportunity and time to develop experimental skills in our seminar that are useful for everyday classroom practice. Therefore, during this new seminar, we impart both knowledge of the fundamental techniques for carrying out experiments in everyday school life, as well as the professional knowledge for embedding experiments in the classroom in a way that promotes learning, while always taking into account the particular needs of prospective physics teachers, and striving to combine teachers' CK and PCK (cf figure 1). 


\section{Experimental competence}

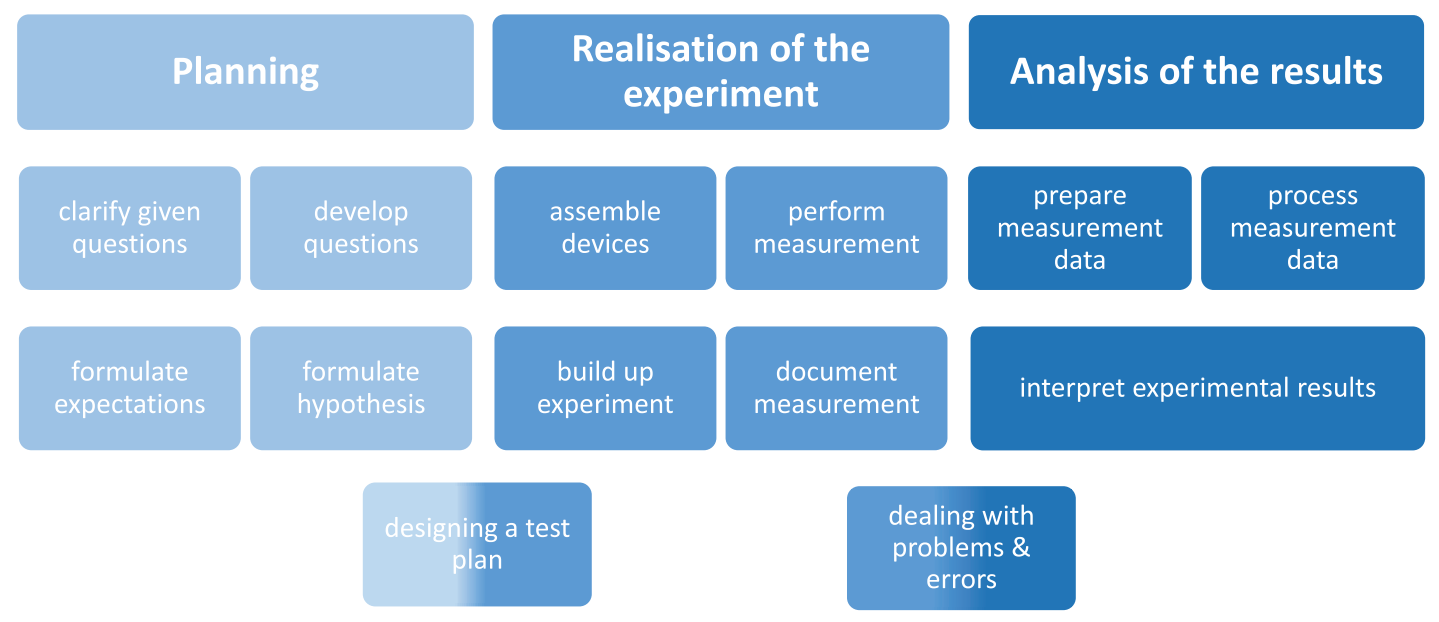

Figure 3. Model of experimental competence as presented by Schreiber et al [35, 36]. The central aspect of this model is the concrete implementation of an experiment, focusing on concrete techniques for carrying out experiments.

Core ideas of our seminar are presented in 4 and lastly, we present the results of a pilot study evaluating the seminar ( $\mathrm{cf}$ section 5), providing first empirical evidence that the new seminar concept contributes to the teaching of basic experimental techniques, which are essential for teachers in physics classrooms.

A necessary prerequisite for the valid assessment of experimental competence of students is a model of experimental competence that can actually be put into practice. This is presented in the following section 3 .

\section{Modelling and assessing experimental competence}

\subsection{Modelling experimental competence}

Eickhorst et al define the term experimental competence as a 'latent ability to at least intuitively rule-based planning and implementation of experiments aimed at clarifying a physical question, as well as for the methodically conscious evaluation of the gained data' (translated from [29]) and state that experimental competence shows in performance if the essential CK is accessible.

A distinction between three sub-competences is common in various models of experimental competence $[30,31]$, taking up the presentation of a scientific process of investigation and inquiry [32], namely:

- Finding and setting up hypotheses

- Planning and carrying out experiments

- Analysis of experimental results

Thus, models of experimental competence usually consist of three pillars that can be identified with the phases of experimentation, and mostly only vary with regards to the scope and weighting of the individual sub-competences, as Theyßen et al reveal [33]. In a different model according to [34], however, experimental competence is modelled by means of various subdimensions that are related to experimental problem types.

In the model of Schreiber et al [35, 36], the three main domains planning, realisation, and analysis encompass the characteristic features of the process steps of experimentation, plus two further features in between domains:

In this article, we follow the model presented by Schreiber et al focusing on the concrete realisation of experiments rather than on the planning or on the analysis of data. We claim that 
without the teacher's ability in basic experimentation techniques to carry out experiments, the beneficial embedding in the classroom situation cannot succeed.

\subsection{Assessment of experimental competence}

There are a number of difficulties in the assessment of experimental competences that need to be considered in the test development: In the case of test procedures in written form, experimental activities appear to be underrepresented, casting doubts on content validity [33]. In tests with real experiments, only exemplary experimental tasks can be demanded, which prevents reliable measurement of the construct experimental competence.

Theyßen et al [33] provide a test instrument that is intended to take both these aspects into account: With their computer-based test procedure, the authors facilitate the assessment of experimental competences of school pupils by means of interactive simulations instead of real experiments. Thereby, not only the results of the experiments are included in the rating, but also the process of experimentation [36]. This on-screen procedure allows for the reliable and valid assessment of experimental skills even in large scale assessments [37]. For results of the pilot studies, see [38]: For example, through convergent validation using simulations and hands-on testing, it was found that students' on-screen performances on this browser-based test instrument can indeed be interpreted as a measure of the students' experimental competence [39]. This is important, because in previous studies the exchangeability of hands-on procedures, written tests, and computerbased procedures had been examined, cf [40-42], revealing only low correlations between hands-on assessments and the other procedures.

The authors provide 12 test units, that can be used in different configurations to build test booklets (cf table 1). In every test unit, a common school experiment from either optics, mechanics or electricity is chosen as a central topic. Each unit is made up of different items in order to cover all of the three areas Planning, Realisation of the experiment and Analysis of the results within every unit.
Theyßen et al [33] extracted the experiments for their test instrument from detailed curriculum analyses and expert surveys. This shows that teachers in training consider these experiments to be relevant in classroom practice. In particular, it is required that physics teachers themselves have the experimental competences to carry out these particular experiments, which means this is conducive to content validity. Thus, it seems to be appropriate to empirically assess

(a) the difficulties of prospective teachers with standard experimental situations and

(b) their learning gains within a first pilot study, evaluating the effectiveness of a new seminar concept,

notwithstanding that the test instrument was originally developed for younger pupils.

\section{Seminar on basic experimental techniques}

In this section, we present our seminar concept on basic experimental techniques. We start by giving a brief insight into physics teachers' training in Germany and situate the seminar concept within the curriculum.

\subsection{German physics teacher education}

In a document on the content requirements for the subject disciplines and subject matter didactics in teacher education, the Standing Conference of the Ministers of Education and Cultural Affairs of the Länder in Germany set standards for teacher education [43]. Teacher education in Germany is divided into three phases at different educational institutions; for the German education system concerning physics teachers at secondary school level cf figure 5. In the first phase, competences concerning the subject disciplines, working methods and subject matter didactics [43, p 3] are acquired during the studies at university. With regard to knowledge and working methods, the subject-specific competence profile for physics details that 'knowledge and skills in experimentation and in handling (typical school) equipment' (translated from [43, p 50]) should be acquired 


\section{P Bitzenbauer and J-P Meyn}

Table 1. All units provided by [33]. Four units (two from one topic, two from another) form one test booklet. In our pilot study, evaluating our new seminar concept presented in 4 of this article, we used units E1, E2, O3 and $\mathrm{O} 4$ (in italics) because the topic mechanics is not discussed during our seminar.

\begin{tabular}{|c|c|c|}
\hline Electricity Units & Optics Units & Mechanics units \\
\hline $\begin{array}{l}\text { E1: V-I-charactersistic of a } \\
\text { light bulb }\end{array}$ & $\begin{array}{l}\text { O1: Refraction of light on the semicircle } \\
\text { block }\end{array}$ & M1: Density determination \\
\hline E2: Power of light bulbs & O2: Reflection on the semicircle block & M2: Strech of a rubber band \\
\hline $\begin{array}{l}\text { E3: Parallel circuit of light } \\
\text { bulbs }\end{array}$ & O3: Total reflection & M3: Buoyancy in water \\
\hline $\begin{array}{l}\text { E4: Series circuit of light } \\
\text { bulbs }\end{array}$ & $\begin{array}{l}\text { O4: Determining the focal length of a } \\
\text { lens }\end{array}$ & M4: Inclined plane \\
\hline
\end{tabular}

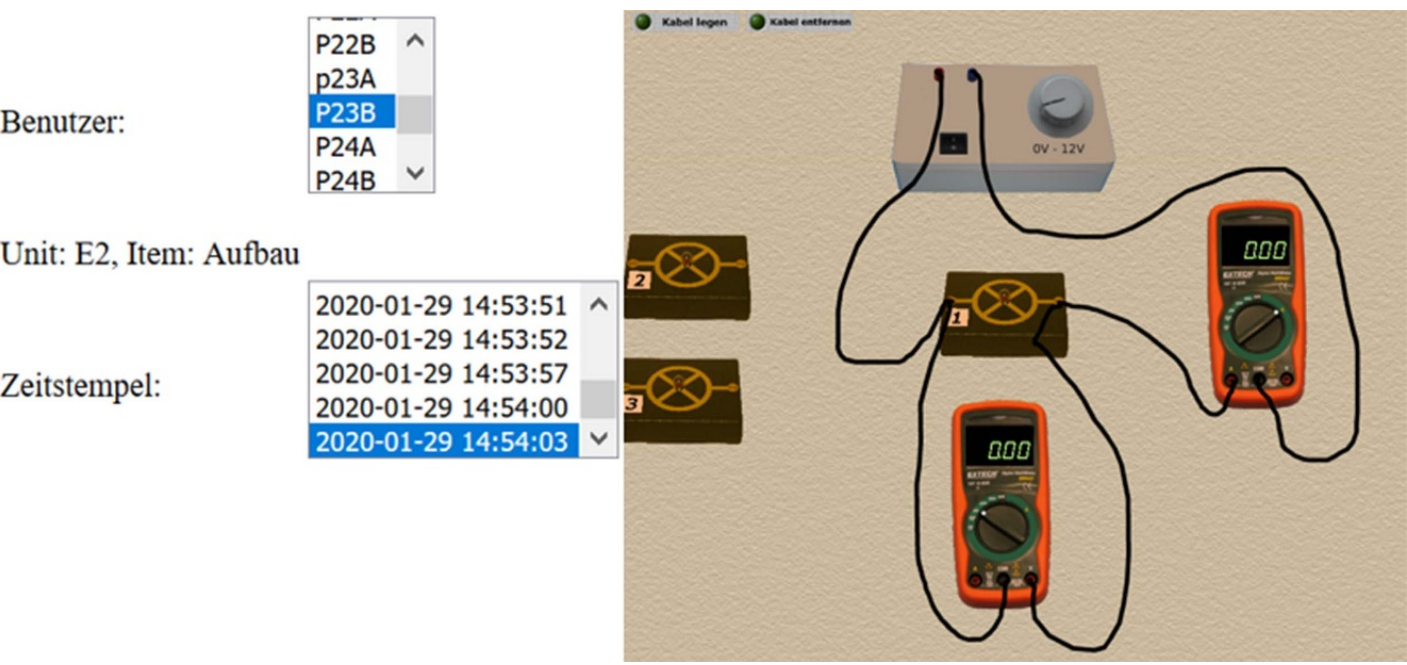

Figure 4. Example for a pupil's solution (screenshot) for an item with the task to measure a lightbulb's V-I-curve as a part of unit E2, reproduced from [33]. For such items with high interactivity, a rating is carried out on a fivestage scale $(0=$ not suitable, $\ldots, 4=$ totally suitable $)$, while the other items are rated on either a three-stage scale or in a dichotomous manner. The detailed coding manual provided by the authors of [33] facilitates an evaluation according to exact criteria.

during the courses at university. Physics laboratory courses are specifically provided in the first phase of teacher education in order to promote these experimental competences.

The seminar concept presented here (cf section 4.2) also aims to promote experimental competences, i.e. it is also dedicated to studying subject knowledge and knowledge of methods. However, we embed this seminar directly into training in physics education: The students attend the experimental seminar alongside a lecture introducing physics education. In our experimental seminar, learners' difficulties are repeatedly taken up and discussed, using the example of basic experimental techniques. In this way, we link the superordinate areas of competence from subject science and subject matter didactics in order to mutually promote $\mathrm{CK}$ and PCK of the students, as explained in section 1 . In the following section, we present the seminar on basic experimental techniques in more detail.

\subsection{Seminar concept on basic experimental techniques}

Our seminar is different to conventional laboratory courses in two aspects. Firstly, assignments are given without any specification on the equipment to be used, and secondly, the whole collection of apparatus which may possibly be 
Fostering experimental competences of prospective physics teachers

\begin{tabular}{|c|c|c|c|}
\hline & phase 1 & phase 2 & phase 3 \\
\hline institution & University & Teacher seminars / schools & $\begin{array}{l}\text { e.g. academies for teacher } \\
\text { training }\end{array}$ \\
\hline timeframe & 5 years ( 3 years BA, 2 years MA) & $1.5-2$ years & $\begin{array}{l}\text { regular participation } \\
\text { throughout the entire } \\
\text { career }\end{array}$ \\
\hline contents & $\begin{array}{l}\text { subject disciplines } \\
\text { experimental physics, theoretical } \\
\text { physics, laboratory courses } \\
\text { educational sciences } \\
\text { physics education, pedagogy and } \\
\text { psychology } \\
\text { school internships }\end{array}$ & $\begin{array}{l}\text { classroom practice with own } \\
\text { responsibility under } \\
\text { supervision and seminars on } \\
\text { - didactics, } \\
\text { - pedagogy, } \\
\text { - psychology, } \\
\text { - school law or } \\
\text { - civic education }\end{array}$ & $\begin{array}{l}\text { any topics concerning } \\
\text { teaching and learning in } \\
\text { schools }\end{array}$ \\
\hline
\end{tabular}

Figure 5. Overview of the three phases in German physics teacher education.

found in the natural sciences collections of secondary schools is available. Easy tasks become difficult because of the additional decisions the students have to make. Therefore, the initial assignments seem to be very simple in the context of a university course.

The first task is to turn on a light bulb. This seems to be an inordinately simple challenge for any physics student who has completed introductory lectures, laboratory courses, and even a lecture on theoretical electrodynamics. It is, however, trickier than it appears. The bulbs are not labelled, except at the socket. The connecting cables have different lengths and colours. Most importantly, there are more than 30 different power supplies on offer. More often than not, one daredevil group goes ahead with a power supply they have seen before and just try their luck. Then, other groups usually follow, but there simply are not enough power supplies of the same kind. At that point, the teacher has to step into the process and ask the students to reflect on their choices. These phases of reflection will occur several times in a session. Soon, everyone realises that inspecting an improper setup is not done to expose its deviser to ridicule, but instead a good opportunity for all participants to learn from mistakes.

The second task is to measure the voltage and current in the light bulb circuit with a digital multimeter. Our observation of how this challenge was handled by participants prompted us to carry out the empirical investigation presented here. We got the distinct impression that measuring voltage and current had not become a student's core competence, even after completing two university laboratory courses. This impression was later confirmed, as we will specify in section 5. It must be stated that our students have easy access to the laboratory outside the lecture period to practice. A teacher is present only occasionally and on request, so students can make perceived blunders without fearing negative comments. A certain amount of spare parts, especially fuses and bulbs, is necessary, but this is a good investment. The students learn to admit mistakes and to be responsible for equipment to be repaired.

In the second class session, a circuit with a light bulb has to be set up again, but this time with a $12 \mathrm{~V} / 100 \mathrm{~W}$ halogen lamp. Several power supplies which have been used successfully before will fail due to insufficient current. When using only suitable power supplies with the minimum current specification of $10 \mathrm{~A}$, what happens is that these lamps differ in brightness significantly, so we end up having to measure the voltage and current again.

It becomes apparent that some of the power supplies, namely transformers without stabilisation, provide a much smaller voltage than the one specified at the dial. A typical value is $9 \mathrm{~V}$ instead of $12 \mathrm{~V}$. The students will most likely have heard about the internal resistance of a power supply, but they have had no occasion to experience the implication of this fact. Some advanced students 
might notice that it is best to adjust the voltage to $12 \mathrm{~V}$ directly at the lamp, because some 100 $\mathrm{mV}$ are lost on the cables. Overall, there are several ways to implement and optimise even a trivial experiment such as the light bulb setup. At this point, it looks like a mere exercise, but it is also applicable later on in optics experiments, where we want to make the available lamps as bright as possible.

The following lessons cover DC and AC circuits, an oscilloscope, digital data acquisition, and optics, including diffraction and elementary spectroscopy. Due to limited time, we do not cover mechanics and thermodynamics. The reasoning behind this is that it appears to make more sense to look at a few exemplary experiments in depth, rather than skimming over the entire field of high school physics. The underlying principle is always the same: Avoid the tried and trusted recipe, but instead analyse the task with a physicist's mind. For example: Is the voltage drop over a $1 \mathrm{~m}$ long laboratory cable significant?-Do not speculate or ask the internet, but calculate, and confirm your calculations by exact measurements.

The final assignment is to resolve the dublett spectral line of sodium at 589.0 and $589.6 \mathrm{~nm}$. Using a 1200 lines $\mathrm{mm}^{-1}$ reflective diffraction grating and a simple projection of the slit image onto a screen yields a result easily. A challenge is posed by replacing the 1200 lines $\mathrm{mm}^{-1}$ grating with gratings of a smaller period. Depending on the size of the setup, it becomes necessary to use a magnifying glass to look at the delicate spectral lines. By using an eyepiece to look directly towards the lamp, the subjective brightness is strongly enhanced. The green dublett is observed additionally, providing an occasion to talk about spin orbit interaction. Further reduction of dispersion by using lower resolution gratings or even prisms forces the students to improve the alignment of optical elements. With simple achromatic lenses and an F2 prism of $60 \mathrm{~mm}$ base length, one can observe a diffraction-limited image, if all parts are aligned perfectly. Only a few students' setups yield the diffraction limit, but everyone handles the job much better than during the first approach. The quality of alignment is not judged by the teacher, but by nature. A majority of students take the chance to practice in the open laboratory.
In a consecutive seminar, students are asked to search literature for innovative experiments on a certain subject and give a talk with demonstrations. Often it is necessary to alter a setup because an important component is not available. After coming up with the present seminar concept, we have noticed a significant improvement in the quality of demonstrations.

\section{Pilot study \\ 5.1. Research question, sample and data collection}

We used the test instrument presented in section 3 using Units E1, E2, O3, O4 in a pilot study with a pre-/post-test design in order to determine the development of experimental competences of prospective physics teachers initiated by our seminar concept (cf section 4.2). Our research question for the pilot study was: To what extent does the seminar concept advance experimental competences of prospective physics teachers, especially with regards to the realisation of experiments?

We surveyed the experimental competences of $N=22$ (14 male, 8 female) physics teacher students pre and post participating in our seminar during winter term 2019/20. At this point, all participants in the pilot study were in their fifth semester. The training in physics education, and thus also the seminar presented here, is scheduled only after successful participation in the introductory lectures on experimental physics. Hence, in addition to two introductory laboratory courses, all of our participants had successfully completed the introductory lectures on experimental physics in their first four semesters before participating in our seminar, specifically on mechanics, thermodynamics, electricity, optics, and atomic physics. In particular, the participants of our pilot study did not attend any other laboratory courses during this winter term 2019/20.

\subsection{Data analysis}

In this article, we use the median Mdn as well as the mean value $m$ and standard deviation $\sigma$ to describe our data. We performed nonparametric tests to indicate differences: The Wilcoxon test was used to investigate learning gains 
Fostering experimental competences of prospective physics teachers

between pre- and post-test. Gender differences were investigated using the Mann-Whitney U test. Each effect was considered statistically significant when the $p$-value was below the $5 \%$ threshold. We also report the effect of size measure in terms of Pearson's $r$ to judge the magnitude of statistically significant effects [44].

The authors of reference [45] suggest spiderwebs to represent the degree of students' various experimental subcompetences [46]. In our pilot study, we used spider-webs to summarise and graphically illustrate students' experimental subcompetences pre and post the seminar to provide feedback to the participants on the areas of experimentation in which they had developed their skills well or where there was still room for improvement. For this purpose, an individual spider-web was created for each student based on the pre- and post-test results. Therefore, we calculate students' relative test scores (percentage of maximum achievable points ranging from $0 \%$ to $100 \%$ ) in the items corresponding to the following subcompetences (cf figure 3 ) across different units (cf table 1) pre and post our seminar:

- designing a test plan: seven items ${ }^{1}$ in the whole test, at least one in each unit (achievable score: 20 points)

- assemble devices and build up experiments: four items in the whole test, one in each unit (achievable score: 16 points)

- perform and document measurement: four items in the whole test, one in each unit (achievable score: 16 points)

- prepare and process measurement data: five items in the whole test, at least one in each unit (achievable score: 6 points)

- interpret experimental results: three items in the whole test, one in unit $\mathrm{E} 1$, one in unit $\mathrm{O} 3$ and one in unit $\mathrm{O} 4$ (achievable score: 3 points)

In the original form according to [45, p 6], these spider-webs included two further subcompetences, namely the development of questions and the formation of hypotheses. However, both aspects were not part of the test we used to assess

\footnotetext{
${ }^{1}$ For the specific designs of the individual items, we refer to the work of the test's developers [33].
}

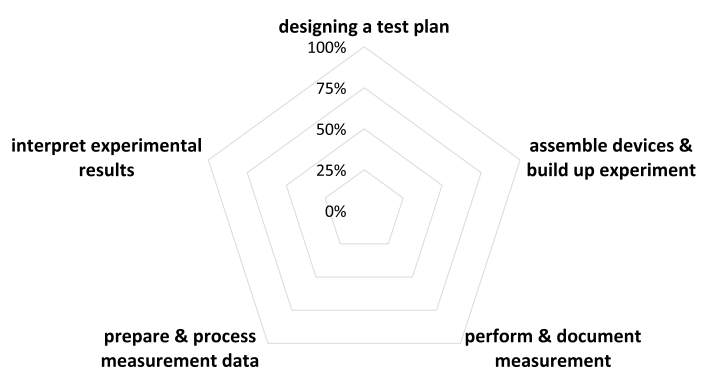

Figure 6. Spider-web tool to summarise students' experimental competences. By plotting participants' relative test scores on the corresponding items of the test on experimental competences (cf section 3.2), competence networks result. These give a graphical overview of possible strengths and show in which areas there is still a need of improvement.

prospective physics teachers' experimental competence, because the focus of our new seminar concept is on the realisation of experiments. For this reason, we did not consider these two subcompetences for the spider-webs presented in this article (cf figure 6).

\subsection{Item statistics and reliability}

In the test, a total of 61 points could be achieved across the four units $(\alpha=0.68)$.The evaluation was based on classical test theory. The coding was carried out by two independent raters with a high level of agreement $(\kappa=0.81,95 \%$ CI [0.69; 0.93]).

The item difficulties are predominantly in the middle range of $0.2-0.8$ [47] as can be seen in figure 7 , although the test instrument was developed and piloted for a less physicseducated group of people (pupils in schools, $\mathrm{cf}$ section 3.2).

For the three subscales Planning (eight items across all four units, $\alpha=0.31$ ), Realisation (eight items across all four units, $\alpha=0.57$ ) and Analysis of results (eight items across all four units, $\alpha=0.40)$ Cronbach's $\alpha$ as estimator of the internal consistency of a scale is below the accepted threshold of 0.70 due to a wide range of contents and actions covered. However, the subscales are still used for this pilot study, because it is not intended to differentiate between different ability levels with them, but rather to gain insight into those components of experimental competence in 


\section{P Bitzenbauer and J-P Meyn}

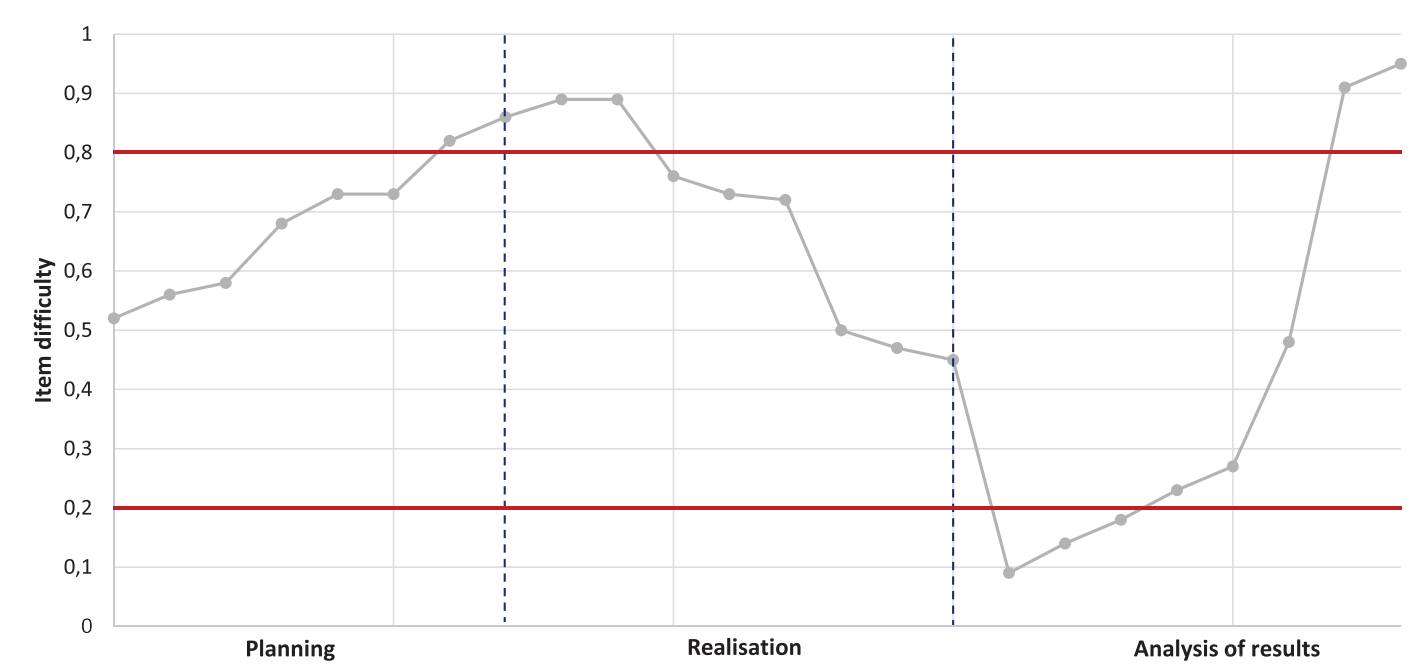

Figure 7. Item difficulties for all 24 items shown across all units sorted by the three areas of the underlying model of experimental competence. The red lines represent the accepted limits for moderate item difficulty. This figure suggests that overall the test is in accordance with the test persons' skills (mean item difficulty 0.59) at the pre-test point in time, although it was developed for assessing pupils' experimental competences. The average discrimination index of the test items equals 0.23 .

which learning gains are initiated by our new experimental seminar in particular.

\subsection{Pre-test results}

5.4.1. Test scores. In the pre-test, the students achieved an average of $m=38$ points $(\sigma=9)$ ranging from $32 \%$ (one student) to $87 \%$ (one student), which corresponds to $63 \%$ of the possible total score in average. The median value of the total samples' pre-test scores is $\mathrm{Mdn}=40$ points. A Mann-Whitney U test indicates statistically significant differences in test scores between male $(\mathrm{Mdn}=43)$ and female $(\mathrm{Mdn}=35)$ students in the pre-test $(U=25.5, Z(20)=-2.10, p<0.05$; $r=0.33$ ). A detailed overview of the descriptive statistics on the pretest results including median, mean value and standard deviation of the total sample and for males and females separately is given in table 2 .

In the following subsections, we take a closer look at several items of special interest and present frequently observed difficulties that prospective physics teachers had with experimental tasks. We limit ourselves to typical mistakes in the realisation of the experiments (or closely related activities).
Table 2. Descriptive statistics on test scores (pre and post) and learning gains, both for the total sample and for males and females respectively. The maximum achievable score in the test was 61 points. Deviations in learning gain values from the difference of the mean values in pre- and post-test are due to rounding.

\begin{tabular}{llccc}
\hline & & Total sample & Males & Females \\
\hline Mdn & pre & 40 & 43 & 35 \\
(test score) & post & 50 & 51 & 45 \\
$m$ & pre & 38 & 41 & 33 \\
(test score) & post & 49 & 51 & 45 \\
$\sigma$ & pre & 9 & 8 & 8 \\
(test score) & post & 4 & 4 & 3 \\
Learning gain & $m$ & 11 & 9 & 12 \\
& $\sigma$ & 8 & 9 & 6 \\
\hline
\end{tabular}

5.4.2. Difficulties in optics. In Unit O3, the test persons had to investigate the dependence of the limit angle for total reflection on the refractive index of the optically denser medium at the transition to air. For this purpose, the students were asked to choose semicircular blocks of different materials $(n>1)$, an angle-measuring disc, and a light source out of a number of distractors in a virtual experiment.

Investigating the sketches made by the students to plan the experiment, two primary types 


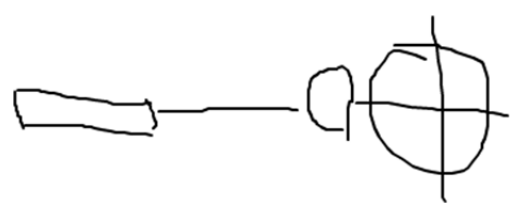

Figure 8. Screenshot of test person P17A's sample sketch. The semicircular block is not placed on the angle measuring disc. In this manner, angles of refraction cannot be measured.

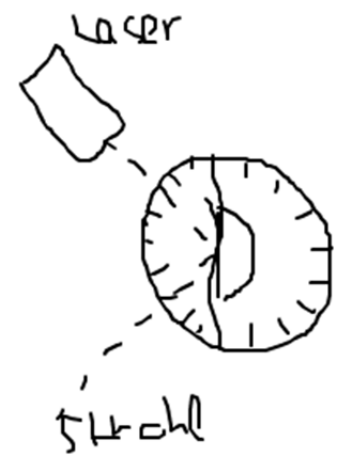

Figure 9. Screenshot of test person P25A's sample sketch. The semicircular block is not placed on the angle-measuring disc correctly. In this manner, total reflection cannot be investigated.

of problems can be pinpointed: One of these problems was that the semicircular block was not placed on the angle disc by $28 \%$ (6 out of 22 ) of the test persons (cf figure 8). This makes it impossible to measure the angles of refraction and thus prevents any meaningful investigation of the problem.

Another 6 of the 22 test persons located the semicircular block on the angle disc, but arranged it incorrectly (cf figure 9). The incident light must hit the round side of the block perpendicularly, so that total reflection can then be investigated on the planar surface. Test persons who offer the flawed solution, or the one mentioned above, appear to lack basic knowledge of geometrical optics.

These problems were not only apparent in the test sketches, but were also evident in the experimental setups, even though helpful interim solutions were accessible. Numerous other inaccuracies, especially in the exact alignment of the semicircular block on the angle disc, were found. This would in effect have prevented proper measurements in real experiments, cf figure 10.

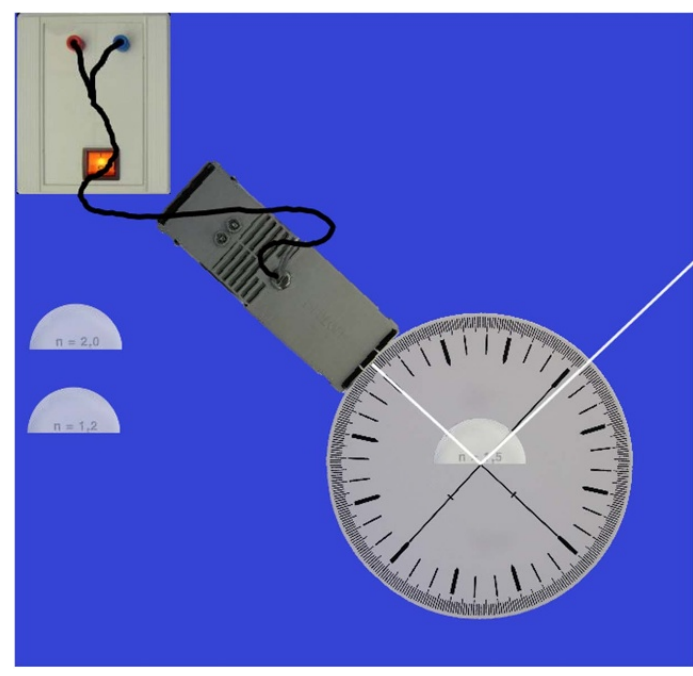

Figure 10. Screenshot of test person P27A's experimental setup. The semicircular block is inaccurately arranged on the angle-measuring disc. Experimental inaccuracies due to students' on-screen operations of the computer simulations are considered by the coding manual provided [33]. But in the case presented here, the inaccuracy is very clear.

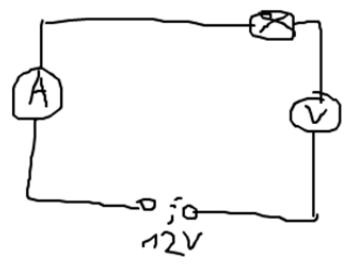

Figure 11. Screenshot of test person P31A's sample sketch. Student P31A suggested measuring voltage in series.

5.4.3. Difficulties in electricity. In Unit E1, the test persons had to measure the V-I-characteristic of a light bulb. For this purpose, the students were able to choose suitable devices such as a digital multimeter, cables, and power supplies out of a number of distractors in a virtual experiment.

In an initial item, the test persons were expected to describe the basic idea of the experiment, i.e. they should be able to explain which physical quantity is varied in the experiment, and which is measured. In this context, some students unwittingly fell for known pre-concepts, as reported in various studies from physics education on the learning about electricity, cf [48-50]. For example, 6 of the 22 respondents $(28 \%)$ claimed 


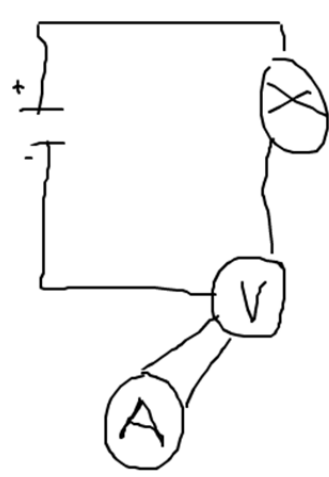

Figure 12. Screenshot of test person P17A's sample sketch. Student P17A suggested measuring voltage in series, with the electrical current parallel to the voltmeter.

that it was not the voltage that needed to be varied with a power supply, but the electrical current.

Other problems arose in the test persons' sketches: some participants (5 out of 22) were apparently unaware that the voltage measurement was a two-point measurement. They suggested measuring the voltage applied to the light bulb in series, or measuring it in parallel with the amperemeter, or vice versa (cf figure 11).

Sometimes, even both errors were revealed in one (cf figure 12); conceptual problems of understanding with regard to the distinction between voltage and electric current become apparent in this case.

It is noteworthy that we observe a lack of basic experimental techniques, which are simply indispensable for professional physics lessons: for example, test persons suggest measuring voltage in series, or measuring the electrical current in parallel ( 3 out of 22, cf figures 2 and 12). The observed errors were not only apparent in the test sketches of the test persons, but also in the experimental setups presented in the virtual experiment. Here, we find errors similar to the ones described above (cf figure 13).

Various experimental setups show that many of the participants do not even know the meaning of the socket assignments on the digital multimeter, and in 3 out of 22 cases, participants neither used the COM-socket, nor did they set the measuring range correctly (cf figure 14).

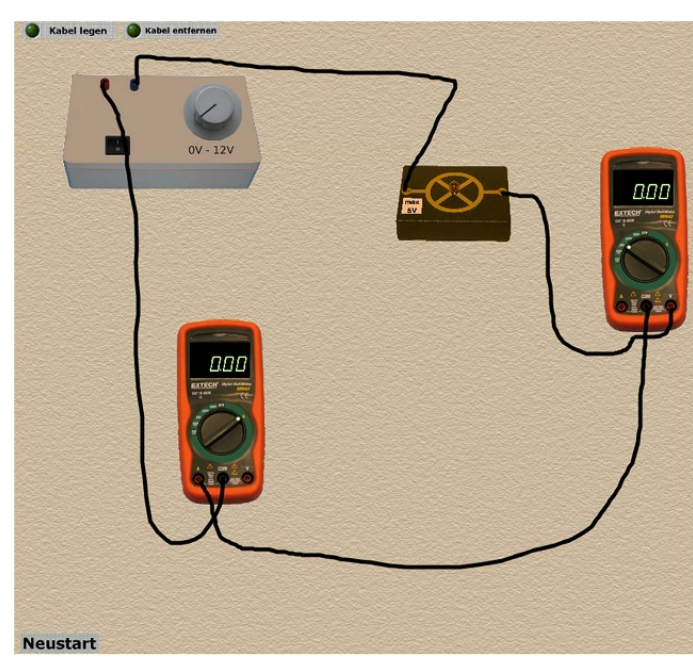

Figure 13. Screenshot of test person P23A's experimental setup, suggesting measurement of the voltage in series to the light bulb.

\subsection{Interim conclusion}

The findings presented in this section-and of the pilot study in general-are not generalisable, due to the small sample. Furthermore, from the findings presented, we do not infer a conclusion about the students' ability to implement experimental tasks on a given setup, as promoted in typical laboratory courses (cf section 2). However, from the pretest results during our pilot study, we conclude that undergraduate prospective physics teachers $(\geqslant 5$ th semester) have a distinct lack of fundamental experimental techniques and show a need for clarification on fundamental technical issues.

\subsection{Post-test results}

The experiments to be set up in the test that we used for our pilot study (cf section 3.2) have not been discussed during the seminar, with the educational objective in mind that the students had to perform a transfer of knowledge. Nevertheless, we need to point out that the subsequent results, from the post-test, are not suitable for differentiating between the different levels of competence of the students; an instrument more suited to the sample would be called for. 
Fostering experimental competences of prospective physics teachers

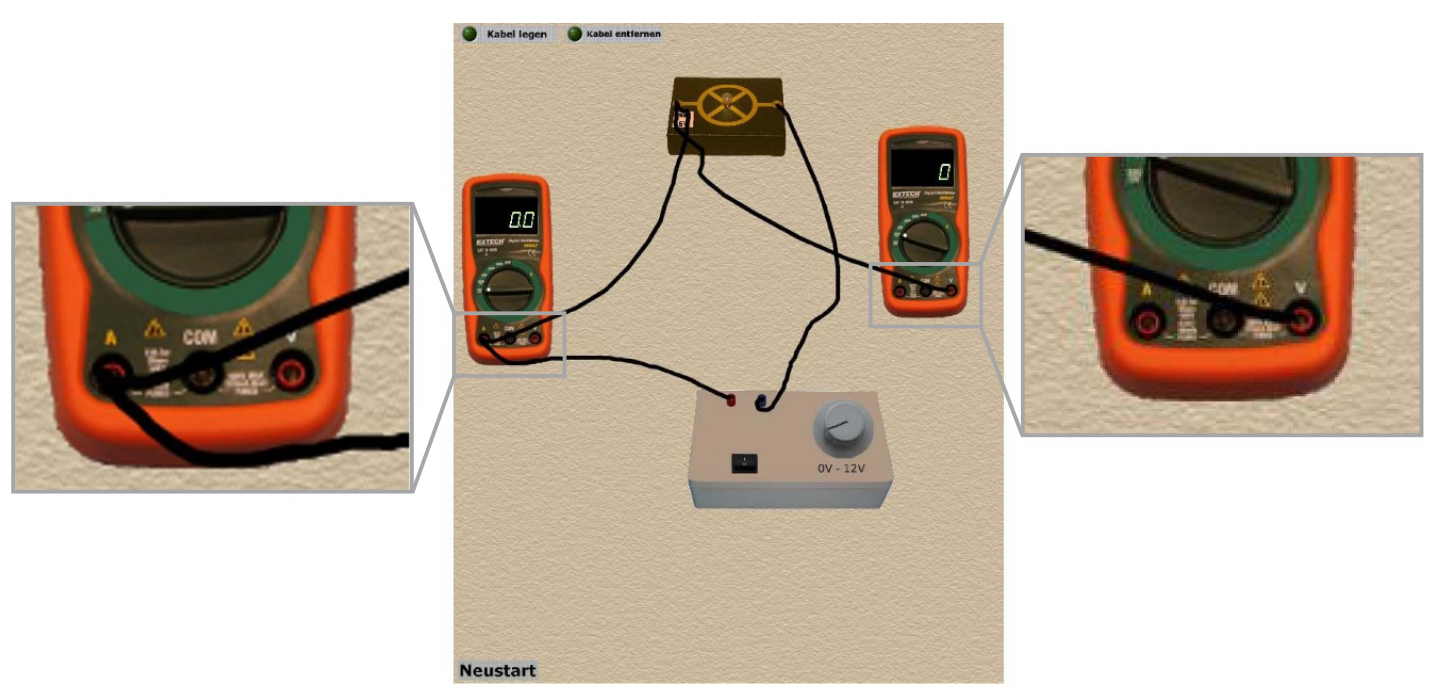

Figure 14. Screenshot of test person P19A's experimental setup. P19A neither used the COM-socket, nor the measuring range was set correctly.

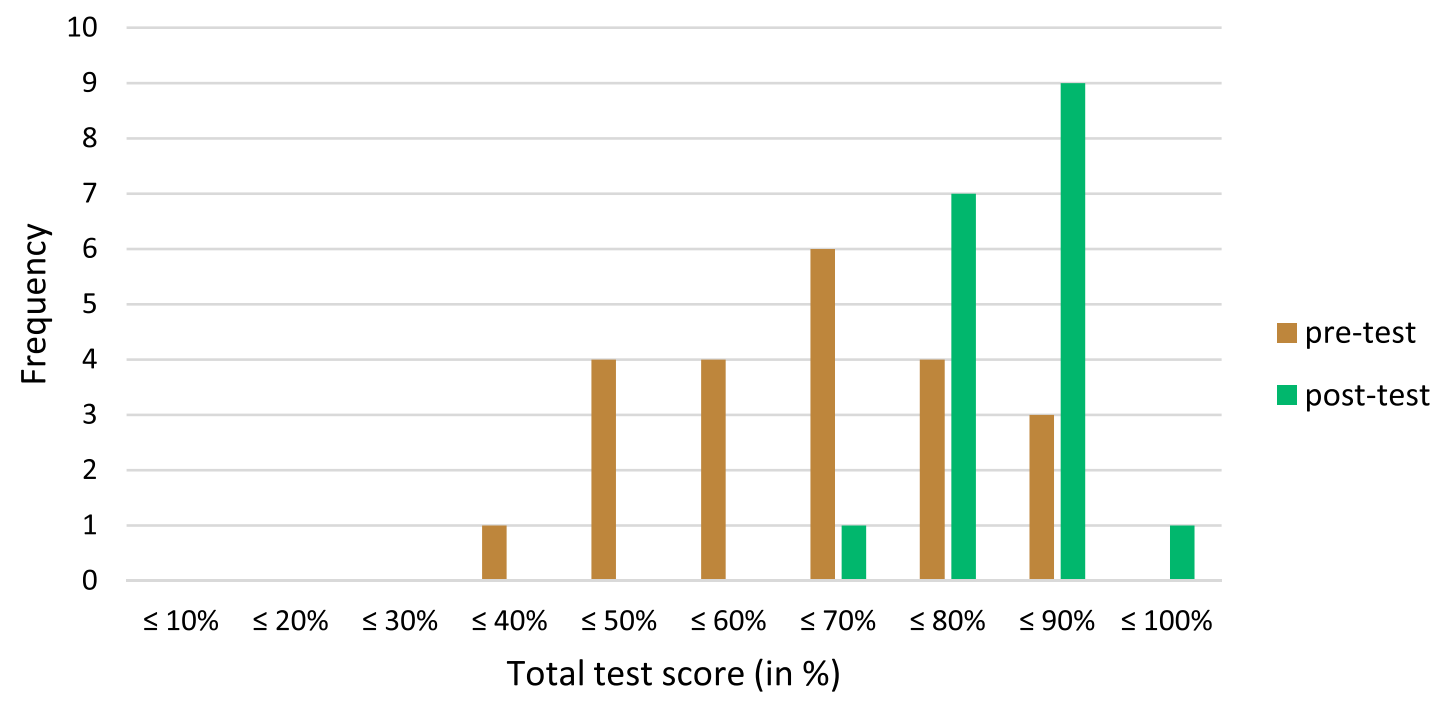

Figure 15. Comparison of pre- and post-test results.

5.6.1. Test scores. In the post-test, the students achieved an average of $m=49$ points $(\sigma=4)$ out of a total possible score of 61 points, which corresponds to $80 \%$ ranging from $68 \%$ (one student) to $95 \%$ (one student). The median of the total samples' post-test scores is $\mathrm{Mdn}=50$ points, while the median in the pre-test was only $\operatorname{Mdn}=40$ points. Thus, we find an average learning gain of 11 points from pre- $(m=38, \sigma=9)$ to post-test ( $m=49, \sigma=4$ ), which is statistically significant after a Wilcoxon test $(Z(17)=-3.27$, $p<0.01 ; r=0.56)$. For an overall summary of the test scores in pre- and post-test, cf table 2 and figure 15 .

A Mann-Whitney U test indicates statistically significant differences in test scores between male $(\mathrm{Mdn}=51)$ and female $(\mathrm{Mdn}=45)$ students in the post-test $(U=7.50, Z(16)=-2.68$, $p<0.01 ; r=0.47)$. However, the observed learning gain of female participants $(m=12, \sigma=6)$ 
P Bitzenbauer and J-P Meyn

Table 3. Pre- and post-test scores $(m \pm \sigma)$ divided by the three subscales Planning, Realisation and Analysis in \% (rounded).

\begin{tabular}{lcc}
\hline Subscale & Pre-test score in $\%$ & Post-test score in $\%$ \\
\hline Planning & $65 \pm 18$ & $91 \pm 8$ \\
Realisation & $67 \pm 17$ & $83 \pm 10$ \\
Analysis & $41 \pm 16$ & $51 \pm 17$ \\
\hline
\end{tabular}

is slightly higher than that of male participants ( $m=9, \sigma=9$ ); therefore there is no indication that the seminar would not allow for gender-sensitive fostering of experimental competences.

Finally, an evaluation of the learning outcomes with a distinction between the individual components planning, realisation and analysis within the model of experimental competence described in section 3.1 suggests that the intervention is effective in exactly those areas for which the seminar was designed: In section 3.1 we explained our focus on the realisation phase, which is necessarily interwoven with the planning phase. We argued that these are the elements essential for successful experimentation in the classroom. The analysis of experimental data plays (frequently unfairly) a subordinate role in the classroom, and prospective physics teachers should especially practice data analysis in the laboratory practicals.

This focus within our seminar is also reflected in the empirical data of our pilot study ( $\mathrm{cf}$ figure 16). While the learning gains in the items on planning an experiment $(Z(17)=-3.44, p<$ $0.001 ; r=0.59)$ and on the realisation of an experiment $(Z(17)=-2.73, p<0.01 ; r=0.47)$ are statistically significant, we find no statistically significant learning gain in the items on analysis of experimental data $(Z(17)=-0.56, p=0.57)$.

A more detailed insight into the students' learning gains can be obtained by taking a look at the subcompetences associated with the individual phases of experimentation. For this purpose, we use the spider-webs introduced in section 5.2. In accordance with the results related to the phases of experimentation we find the following (cf figure 17): while the students make significant progress in the sub-skills that are specifically related to the realisation of the experiments, e.g. designing a test plan, assemble devices \& build up experiment or perform \& document meausrement, we find no or only small progress for the analysis of the data and the interpretation of experimental results. This finding is in line with the expectation because the seminar concept presented in this article very specifically aims to promote basic experimentation techniques.

Lastly, we want to underline these findings on learning gains described by the test scores in a qualitative way. For this purpose, we present some examples of students' post-test work, whose pretest work has been used in section 5.4. to demonstrate typical errors. These no longer appear in the post-test or, if at all, only in individual students' answers, as can be seen from the test scores in the post-test: The students on average reached $91 \%$ of the total possible score in the subscale Planning, and $83 \%$ on average in the subscale Realisation, cf table 3 .

5.6.2. Qualitative description of the students' performance in optics. In the pre-test, the two central problems were that (a) the semicircularblock was not placed on the angle disc by 6 out of 22 test persons and that (b) the angle disc was not arranged correctly (incident light must hit the round side of the block) by further six students. Such problems were not observed in the post-test (cf figure 18).

\subsubsection{Qualitative description of the students'} performance in electricity. In the pre-test, we observed three central difficulties in the students' solutions: For example, five of the test persons were obviously not aware that voltage is always measured in parallel to the lamp. We could no longer observe this error in the post-test.

The cases in which the electric current was measured in parallel in the pre-test (cf figures 2 and 11), no longer occurred in the post-test. Three 
Fostering experimental competences of prospective physics teachers

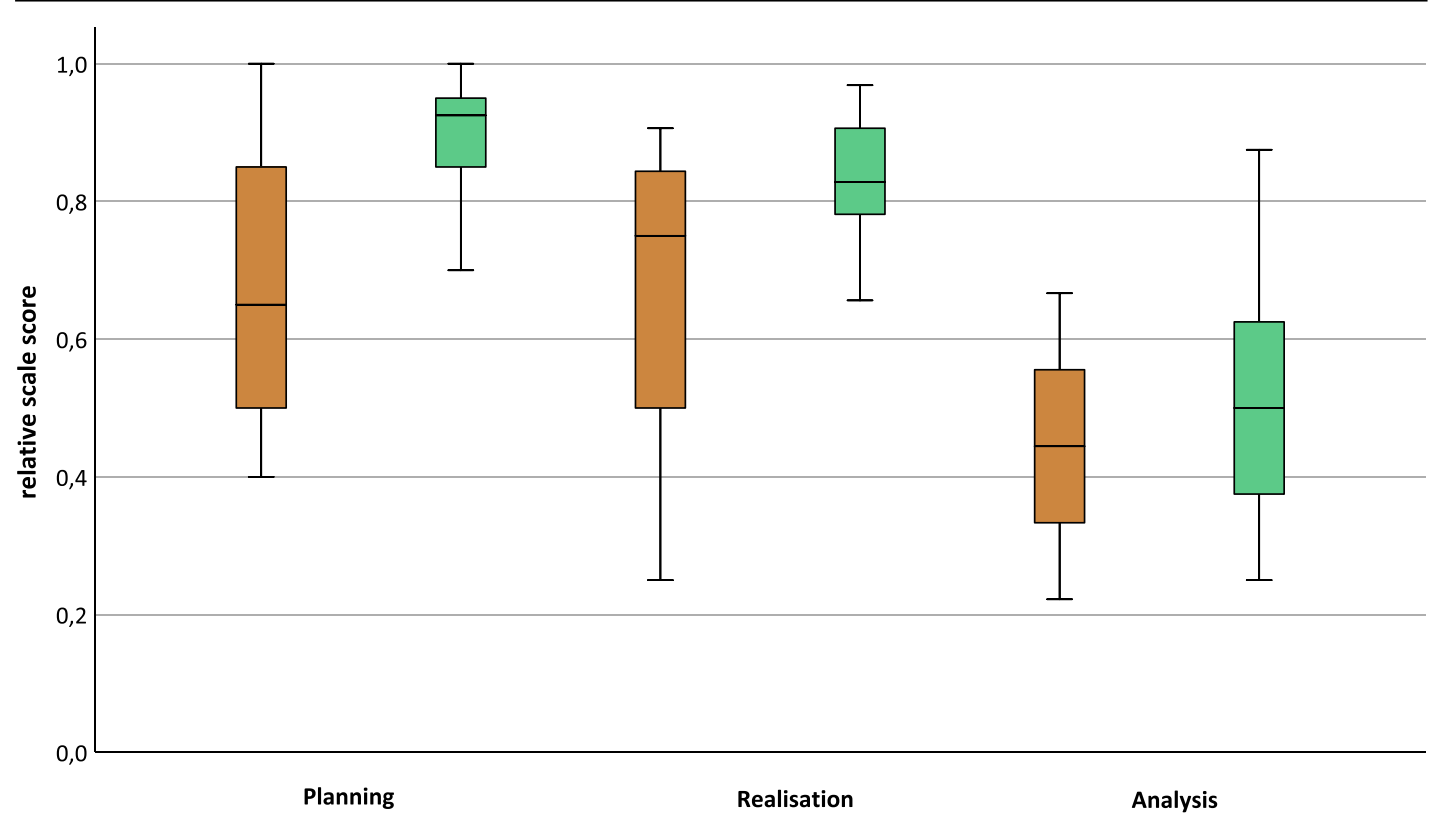

Figure 16. Comparison of pre- (brown) and post-test (green) results (relative scale scores) divided by the three components of our model of experimental competence with $95 \%$ CI. The relative scale score corresponds to the percentage of maximum achievable points per component. This allows a comparison of the three components which the students could achieve different absolute scores in.

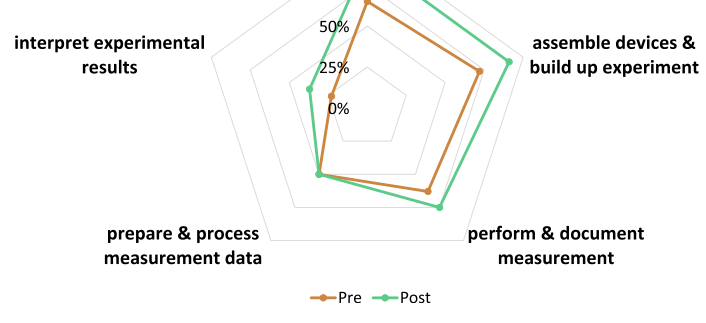

Figure 17. Spider-web to summarise students' experimental competences using relative test scores in the preand post-test (cf section 5.2).

of the 22 test persons did not use the digital multimeters properly in the pre-test (cf figure 13). These errors also did not recur in the post-test, e.g. see test person P19A's experimental setup in the post-test (cf figure 20).

\section{Discussion and conclusion}

Physics teachers are often faced with the challenge of having to set up difficult experiments,

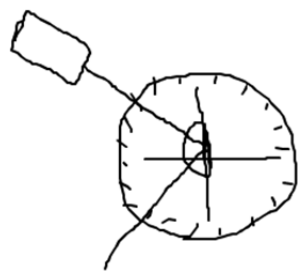

Figure 18. Screenshot of test person P25A's sample sketch in the post-test. The semicircular block is now correctly placed on the angle-measuring disc, unlike in the pre-test, cf figure 8 .

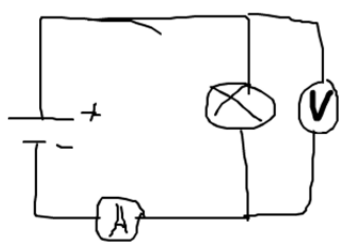

Figure 19. Screenshot of test person P31A's sample sketch in the post-test. The voltage is now measured in parallel to the lamp, unlike in the pre-test (cf figure 10).

which sometimes do not work as planned, or they have to consciously manipulate parameters 


\section{P Bitzenbauer and J-P Meyn}

in order to be able to demonstrate a phenomenon convincingly. This requires experimental competences, especially with regard to basic experimental techniques, as they are repeatedly essential in various fields. In order to foster experimental competences of prospective physics teachers, in this article we presented a new seminar concept. We conducted a first pilot study to evaluate the seminar. Therefore, we used a test instrument from physics education research for the assessment of experimental competences of prospective physics teachers pre and post the seminar. Results from the pre-test underlined that a subset of prospective physics teachers have a lack of fundamental experimental techniques despite formally successful participation in standard laboratory courses and thus, justify the new suggested seminar concept for teacher training.

The created spider-web enables the description of the seminar participants' experimental competences and their development during our seminar (cf figure 17). On the basis of this spider-web it becomes clear that, as expected, the seminar contributes to the acquisition of basic experimental techniques that enable future physics teachers to conduct experiments in physics classrooms. However, further support is needed with regard to the students' ability to correctly process measured data and to correctly interpret experimental results. Therefore, for the future, we are considering an expansion of the seminar with the aim of also promoting the student teachers' competences in data analysis that are necessary for classroom practice.

But also for the individual students the use of the spider-webs proves to be fruitful for the diagnosis of experimental competence. The transition of the students' competency network at the beginning of the seminar to that from the posttest point in time allows for a targeted examination of the learning outcome with regard to the individual subcompetences. In this way, students can be given a concrete recommendation for their further learning process. We did this for all participants in our pilot study and we conclude by giving two examples. Student P17A, for example, acquired less than $50 \%$ of the achievable points in all subcompetences in the pre-test (cf figure 21). In the post-test, he increased to over $75 \%$ of the achievable points in the subskills designing a test

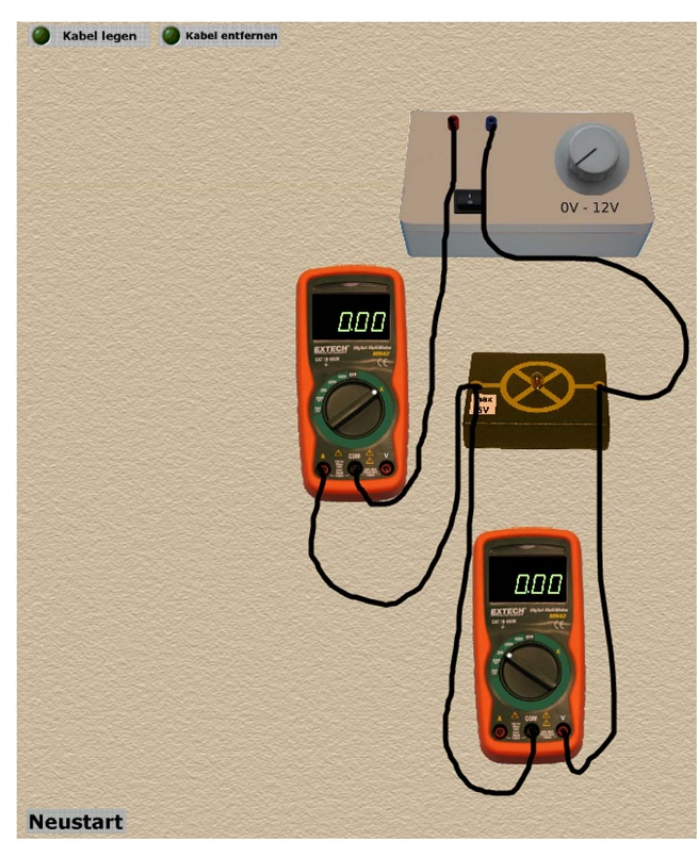

Figure 20. Screenshot of test person P19A's sample sketch in the post-test using the COM-socket and the correct measuring range.

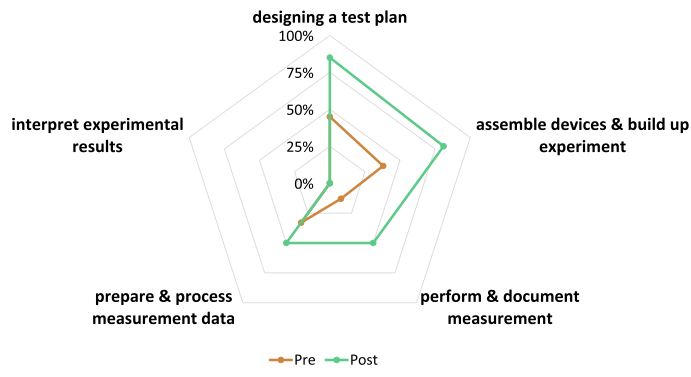

Figure 21. Spider-web to summarise P17A's experimental competences using relative test scores in the preand post-test (cf section 5.2).

plan and assemble devices \& build up experiment. With regard to the competences relating to preparing, evaluating and analysing data, however, the participant remained in the range up to about $50 \%$ of the achievable points.

In contrast to P17A, student P12A represents an example of a subject for whom significant learning gains were observed between pre- and post-test collection with respect to all sub-areas of experimental competence (cf figure 22).

In summary, based on the results of the post-test, we find a significant learning gain with 
Fostering experimental competences of prospective physics teachers

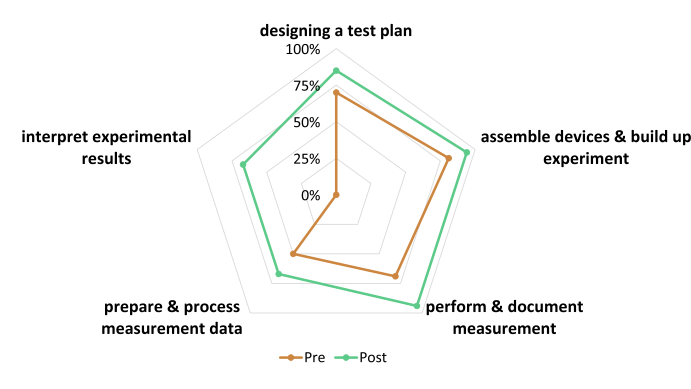

Figure 22. Spider-web to summarise P12A's experimental competences using relative test scores in the preand post-test (cf section 5.2).

respect to the experimental competences of the seminar participants. This can be interpreted as a first empirical evidence for the learning effectiveness of our new seminar concept. However, despite the promising results of the pilot study presented in this article, further research is needed to tackle limitations: More target group-specific instruments need to be used to assess experimental competences in order to conduct more detailed studies with larger samples. In addition, we want to use qualitative methods to investigate in more detail what students see as the causes of their difficulties with fundamental experimental techniques and which elements of the seminar presented here specifically contribute to an increase in learning in their eyes. A comparison of results from such interviews with previous findings from the literature (cf section 2) can contribute to a systematic refinement of our seminar concept. This will be part of further research.

\section{Data availability statement}

The data that support the findings of this study are available upon reasonable request from the authors.

\section{Acknowledgments}

We would like to thank Heike Theyßen (University of Duisburg-Essen) for providing us with the test instrument for the assessment of experimental competences that was developed by her within the joint project MeK-LSA, together with Horst Schecker (University of Bremen) and Knut Neumann (IPN Kiel). We also thank the participants of our pilot study. We would also like to thank the referees for their constructive feedback, which helped to improve the manuscript.

\section{Ethical statement}

Authors acknowledge that the research was conducted anonymously, that consent was obtained from all identifiable participants, and that all identifiable participants are informed about the publication of the results of this study.

The data that support the findings of this study are available upon request from the author.

\section{ORCID iDs}

Philipp Bitzenbauer (ㄴ) https://orcid.org/00000001-5493-291X

Jan-Peter Meyn (1) https://orcid.org/0000-00018036-491X

Received 19 January 2021, in final form 24 March 2021 Accepted for publication 30 April 2021

https://doi.org/10.1088/1361-6552/abfd3f

\section{References}

[1] Hart C, Mulhall P, Berry A, Loughran J and Gunstone R 2000 J. Res. Sci. Teach. 37 655-675

[2] Börlin J 2012 Das Experiment als Lerngelegenheit. Vom Interkulturellen Vergleich des Physikunterrichts zu Merkmalen Seiner Qualität (Berlin: Logos)

[3] Kalthoff B, Theyßen H and Schreiber N 2018 Int. J. Sci. Educ. 40 1305-1326

[4] Baumert J and Kunter M 2006 Zeitschrift für Erziehungswissenschaft 9 469-520

[5] Baumert J, Kunter M, Blum W, Brunner M, Voss T and Jodan A 2010 Am. Educ. Res. J. 47 133-80

[6] Cauet E, Liepert S, Kirschner S, Borowski A and Fischer H E 2015 Revue Suisse des sciences de l'éducation 37 462-79

[7] Kulgemeyer C and Riese J 2018 J. Res. Sci. Teach. 55 1393-418

[8] Barendsen E and Henze I 2019 Res. Sci. Educ. 49 1141-75

[9] Baxter J A and Lederman N G 1999 Assessment and measurement of pedagogical content knowledge Examining Pedagogical Content Knowledge (Dordrecht: Kluwer) pp 147-61

[10] AAPT 2014 AAPT Recommendations for the Undergraduate Physics Laboratory 
Curriculum American Association of Physics Teachers www.aapt.org/ resources/upload/labguidlinesdocument_ ebendorsed_nov10.pdf

[11] Holmes N G and Smith E M 2019 Phys. Teach. $57296-9$

[12] Holmes N G and Wieman C E 2018 Phys. Today $7138-45$

[13] McDermott L C and Redish E F 1999 Am. J. Phys. 67 755-67

[14] Wieman C E and Holmes N G 2015 Am. J. Phys. 83 972-8

[15] Wieman C E 2015 Phys. Teach. 53 349-51

[16] Zwickl B M, Hu D, Finkelstein N and Lewandowski H J 2015 Phys. Rev. ST. Phys. Educ. Res. 1020113

[17] Holmes N G and Wieman C E 2016 Phys. Rev. Phys. Educ. Res. 12020103

[18] Holmes N G, Olsen J, Thomas J L and Wieman C E 2017 Phys. Rev. Phys. Educ. Res. 13010129

[19] Wilcox B R and Lewandowski H J 2017 Phys. Rev. Phys. Educ. Res. 13020110

[20] Smith E M, Stein M M, Walsh C and Holmes N G 2020 Phys. Rev. X 10011029

[21] Smith E M and Holmes N G 2020 Phys. Rev. Phys. Educ. Res. 16020150

[22] Welzel M, Haller K, Bandera M, Hammelev D, Koumaras P, Niedderer H, Paulsen A, Robinault K and Aufschnaiter S 1998 Didaktik Naturwissenschaften 4 29-44

[23] Usembayeva I, Ramankulov S, Berdi D, Saparbekova G and Ualikhanova B $2015 \mathrm{Am}$. J. Appl. Sci. 12 636-43

[24] Edmondson K M and Novak J D 1993 J. Res. Sci. Teach. $30547-59$

[25] Berry A, Mulhall P, Loughran J J and Gunstone R F 1999 Australian Sci. Teach. J. 45 27-31

[26] Kurbanbekov B A, Turmambekov T A, Baizak U A, Saidakhmetov P A, Abdraimov R T, Bekayeva A E and Orazbayeva K O 2016 Int. J. Environ. Sci. Edu. 11 13069-78

[27] Holmes N G, Wieman C and Bonn D A 2015 Proc. Natl Acad. Sci. USA 112 11199-204

[28] Hofstein L and Kind P M 2012 Learning In and From Science Laboratories (Dordrecht: Springer) pp 189-207

[29] Eickhorst B, Dickmann M, Schecker H, Theyßen $\mathrm{H}$ and Neumann K 2015 Messung experimenteller Kompetenz im Large-Scale: Bewertung experimenteller Aufgaben Heterogenität und Diversität - Vielfalt der Voraussetzungen im Naturwissenschaftlichen Unterricht (Kiel: IPN) pp 169-71

[30] Hammann M 2004 Math Naturwiss. Unterr. 57 196-203
[31] Emden M and Sumfleth E 2016 Int. J. Sci. Math. Educ. 14 29-54

[32] Klahr D 2002 Exploring Science: The Cognition and Development of Discovery Processes (Cambridge, MA: The MIT Press)

[33] Theyßen H, Schecker H, Neumann K, Eickhorst B and Dickmann M 2016 Physik und Didaktik in Schule und Hochschule 1/15 26-48

[34] Metzger S, Gut C, Hild P and Tardent J 2014 Modelling and assessing experimental competence: an interdisciplinary progress model for hands-on assessments $E$-Book Proc. ESERA 2013th Conf.: Science Education Research for Evidence-Based Teaching and Coherence in Learning (European Science Education Research Association)

[35] Schreiber N, Theyßen H and Schecker H 2009 Physik und Didaktik in Schule und Hochschule 8 92-101

[36] Schreiber N, Theyßen H and Schecker H 2012 Experimental competencies in science: a comparison of assessment tools E-Book Proc. ESERA 2011th Conf.: Science Learning and Citizenship (European Science Education Research Association) pp 66-72

[37] Dickmann M, Eickhorst B, Theyßen H, Neumann K, Schecker H and Schreiber N 2014 Measuring experimental skills in large-scale assessments: developing a simulation-based test instrument $E$-Book Proc. ESERA 2013th Conf.: Science Education Research for Evidence-Based Teaching and Coherence in Learning (European Science Education Research Association)

[38] Dickmann M 206 Messung von Experimentierfaehigkeiten Validierungsstudien zur Qualität Eines Computerbasierten Testverfahrens (Berlin: Logos) [Measurement of experimental skills-Validation studies on the quality of a computer-based test procedure]

[39] Schecker H, Neumann K, Theyßen H, Eickhorst B and Dickmann M 2016 Z. Didaktik Naturwissenschaften 22 197-213

[40] Baxter G P and Shavelson R J 1994 Int. J. Educ. Res. 21 233-350

[41] Shavelson R J, Ruiz-Primo M A and Wiley E W 1999 J. Educ. Meas. 36 61-71

[42] Stecher B M, Klein S P, Solano-Flores G, McCaffrey D, Robyn A and Shavelson R J 2000 Appl. Meas. Educ. 13 139-160 
Fostering experimental competences of prospective physics teachers

[43] Kultusministerkonferenz 2019

Ländergemeinsame inhaltliche Anforderungen für die Fachwissenschaften und Fachdidaktiken in der Lehrerbildung www.kmk.org/fileadmin/Dateien/ veroeffentlichungen_beschluesse/2008/ 2008_10_16-Fachprofile-Lehrerbildung.pdf (opened 3 February 2021)

[44] Hemphill J 2003 Am. Psychol. 58 78-9

[45] Maiseyenka V, Schecker H and Nawrath D 2013 Physik und Didaktik in Schule und Hochschule 1 1-17

[46] Haagen-Schützenhöfer C and Joham B 2018 CEPS J. 8 9-34

[47] Kline T J B 2005 Psychological Testing. A Practical Approach to Design and Evaluation (Thousand Oaks, CA: Sage)

[48] Cohen R, Eylon B and Ganiel U 1983 Am. J. Phys. 51 407-12

[49] Shipstone D M 1984 Eur. J. Sci. Educ. 6 185-98

[50] Shipstone D M, Rhöneck C v, Jung W, Kärrqvist C, Dupin J J, Johsua S and Licht P 1988 Int. J. Sci. Educ. 10 303-16

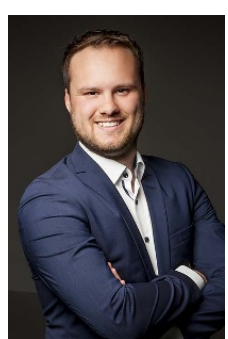

Philipp Bitzenbauer holds a $\mathrm{PhD}$ in Physics Education from the University of Erlangen. His research interests include classroom experimentation, the empirical investigation of learning processes in quantum physics and teaching quantum technologies for future workforce. In addition to his research activities, he works as a secondary school teacher in physics.

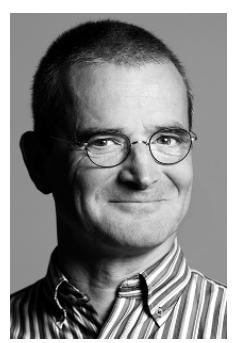

Jan-Peter Meyn has a diploma and PhD from the University of Hamburg. After a decade of research in laser physics, he became a physics teacher at a secondary school. Since 2005 he is Professor of Physics Education at the University of Erlangen-Nürnberg. Photography: Glasow. 